\title{
ON-LINE AND POST-MORTEM WEAR MEASUREMENT OF STATIC COUNTERPART IN A BALL-ON-DISK TEST
}

\author{
Y. Pérez Delgado ${ }^{1}$, K. Bonny ${ }^{1}$, P. De Baets ${ }^{1}$, V. Rodriguez Fereira ${ }^{1}$, P. Neis ${ }^{1,2}$, J. Sukumaran ${ }^{1}$, \\ O. Malek ${ }^{3,4}$, J. Vleugels ${ }^{3}$, B. Lauwers ${ }^{4}$. \\ ${ }^{1}$ Ghent University, Laboratory Soete, Belgium \\ ${ }^{2}$ Federal University of Rio Grande do Sul, Brazil \\ ${ }^{3}$ Catholic University of Leuven, Metallurgy and Materials Engineering Department, Belgium \\ ${ }^{4}$ Catholic University of Leuven, Mechanical Engineering Department, Belgium
}

\begin{abstract}
WC binderless ceramics. The tests were conducted at room temperature and atmospheric conditions according to the ASTM G99-95a standard. Silicon carbide ( $\mathrm{SiC}$ ) balls were used as static counterpart. The tests were performed at a rotating sliding speed of $0.3 \mathrm{~m} / \mathrm{s}$ and an initial mean Hertzian contact pressure of $1.9 \mathrm{GPa}$. The disk specimens were surface finished by grinding. On-line monitoring and post-mortem analysis with two independent techniques, i.e., surface profilometry and optical microscopy, were used to elucidate the tribological characteristics of the studied material. Results of the post-mortem measurements were compared to a geometrical wear model for calculation of the volume of the worn cap of the ball. This calculation appeared to be in good agreement with the on-line wear monitoring. The first $100 \mathrm{~m}$ of sliding was identified as running-in period. Beyond a sliding distance of $100 \mathrm{~m}$ a steady stage in penetration depth was reached, while a higher fluctuation in friction coefficient was observed, which could be attributed to the interaction with wear particles and simultaneous formation and delamination of debris layer, polishing and abrasion.
\end{abstract}

Keywords: friction and wear, binderless carbide, on-line monitoring, post-mortem surface topography, wear model.

\section{INTRODUCTION}

WC-based composites have widely been used in the industry as cutting tools, wire drawing dies, punches [1], etc., due to their elevated wear resistance, thus reducing or minimizing maintenance cost or extending the life-time of the components. These materials are known for having high hardness of up to 9 times higher than steel alloys. WC-based cemented carbides are usually combined with metallic binders such as $\mathrm{Co}$ and $\mathrm{Ni}$. These combinations have some advantages such as high toughness values, however, some drawbacks such oxidation and softening at elevated temperatures are known as well [2].

WC binderless ceramics are developed as replacement of WC- based composites for their interesting wear and corrosion resistance. Nevertheless, new ceramic materials have faced challenges for being investigated by means of wear tests because of their extremely high hardness. It is difficult to find ceramic grades with higher hardness compared to WC-based binderless carbides. Commercial grades such as SiC and BN, are softer compared to WC binderless ceramics used in the present study.

This paper aims to evaluate and compare the friction and wear response of WC binderless ceramic in rotating sliding contact with $\mathrm{SiC}$ balls, and examines how the tribological characteristics are affected by interaction of wear particles. The investigation was carried out by on-line monitoring of friction coefficient and penetration depth (wear). Post-mortem analysis of the generated wear was performed by means of two independent techniques: surface profilometry and optical microscopy. Furthermore, the experimental results were compared to a wear model which presumes a spherical wear cap to be worn off of the ball. 


\section{EXPERIMENTAL}

\subsection{Material properties}

WC binderless ceramic was fully densified by means of pulsed electric current sintering (PECS). Further information on processing and characterization can be found elsewhere [3]. The test specimens display a Vickers hardness $\mathrm{HV}_{10}$ of $2693 \pm 41 \mathrm{~kg} / \mathrm{mm}^{2}$, an E-modulus of $659 \mathrm{GPa}$, a flexural strength of $525 \pm 75$ $\mathrm{MPa}$, fracture toughness $\mathrm{KIC}_{, 10 \mathrm{~kg}}$ of $4.9 \pm 0.3 \mathrm{MPa} \cdot \mathrm{m}^{1 / 2}$ and a density of $15.2 \mathrm{~g} / \mathrm{cm}^{3}$.

The Vickers hardness was measured with indentation load of $98.1 \mathrm{~N}$ for $15 \mathrm{~s}$ (Model FV-700, Future-Tech Corp., Tokyo, Japan). The Young's modulus, E, was obtained by resonance frequency method (ASTM C 1259-94) on a Grindo-sonic (J.W. Lemmens, Elektronika N.V., Leuven, Belgium). The flexural strength was measured on a 3-point bending test set-up (INSTRON 4467, Instron Corp., USA) with a span of $20 \mathrm{~mm}$. The fracture toughness, $\mathrm{KIC}_{10 \mathrm{~kg}}$ was obtained by Vickers indentation [4].

The WC binderless specimens were ground with a diamond grinding wheel (type D46SW-50-X2, Technodiamant, The Netherlands) on a Jung grinding machine (JF415DS, Jung, Germany) to a thickness of $4 \mathrm{~mm}$.

The surface roughness of the WC binderless ceramic was measured using surface profilometry (Somicronic $\circledast$ EMS Surfascan 3D, type SM3, needle type ST305) according to the ISO 4228 standard. The resulting Ra was $0.148 \mu \mathrm{m}$.

\subsection{Tribological characterisation}

Wear experiments were conducted on a tribometer (CSM Switzerland, maximum temperature $1000{ }^{\circ} \mathrm{C}$ ) under the configuration of pin on disk. The tests were carried out according to the ASTM G99-95a standard at room temperature and atmospheric conditions. An initial mean Hertzian pressure of $1.9 \mathrm{GPa}$ was applied, together with a sliding speed of $0.3 \mathrm{~m} / \mathrm{s}$ and a testing time of 2.5 hours. SiC balls were used as static counterpart with a diameter of $5 \mathrm{~mm}$ and surface roughness $\mathrm{Ra} 0.025 \mu \mathrm{m}$. The SiC balls display a Vickers hardness $\mathrm{HV}_{10}$ of $2500 \mathrm{~kg} / \mathrm{mm}^{2}$, an E-modulus of $410 \mathrm{GPa}$, a flexural strength of $400 \mathrm{MPa}$, fracture toughness $\mathrm{KIC}_{10 \mathrm{~kg}}$ of $4.5 \mathrm{MPa} \cdot \mathrm{m}^{1 / 2}$ and a density of $3.1 \mathrm{~g} / \mathrm{cm}^{3}$ (specifications given by the supplier).

Post-mortem analysis of the SiC balls was conducted by means of two independent techniques: 2D surface topography scanning and optical microscopy. The measured dimensions of the worn ball were compared to a geometrical model assuming the ball to wear according to a spherical cap.

\section{RESULTS AND DISCUSSION}

Figure 1 shows on-line recorded friction coefficient and penetration depth curves for WC binderless ceramic flat versus $\mathrm{SiC}$ ball combinations using a sliding speed of $0.3 \mathrm{~m} / \mathrm{s}$, an initial Hertzian contact pressure of 1.9 $\mathrm{GPa}$ and a sliding distance of $2800 \mathrm{~m}$. Within the whole wear test, the dynamic friction coefficient of the regarded tribological pairs of WC binderless flats versus SiC balls was measured to be between 0.42 and 0.62 .

Moreover, dynamic friction coefficient appears to vary as function of sliding distance, that is to say, it increases during the first meters of sliding (approximately $30 \mathrm{~m}$ ), subsequently declines and increases again. After a running-in stage, the friction coefficient curve is increasing until an equilibrium situation is reached. Beyond a sliding distance of $500 \mathrm{~m}$, the average friction coefficient is found to be 0.57 , however, higher fluctuation of friction coefficient can be observed from $750 \mathrm{~m}$ until $1000 \mathrm{~m}$ as well as within the last $800 \mathrm{~m}$ of sliding distance. It can be attributed to the presence of wear debris particles and continuous breaking and interlocking of sharp particles at the contact surface during sliding [5]. The formation of wear debris particles would basically come from the SiC static counterpart which shows lower hardness compared to the WC binderless disk.

Figure 1 shows the effect of penetration depth as a function of sliding distance as well. The penetration depth curve represents the combined wear of ball and disk. However, it can be noted that the penetration wear is predominantly caused by the wear of the SiC ball due to its lower hardness and lower wear resistance compared to the WC binderless disks. The first 100 meters of sliding correspond to a running-in stage, which can be evidenced by the much steeper slope at initial sliding compared to the slope of the steady-state stage. This is confirmed by the equations in Figure 1 representing the linear approximations of the penetration depth curves at running-in stage and at steady-state. Furthermore, at sliding distances of approximately 1000,1300 and $1500 \mathrm{~m}$, a 'negative' wear is noticed in the penetration curve, which could be explained in terms of a wear debris layer being formed at the contact surface. This behaviour is reflected in the corresponding friction curve, displaying higher fluctuations just before the sliding distances at which the 
'negative' wear occurs. This phenomenon could indeed be related to the building up of a wear debris layer which breaks off later on.

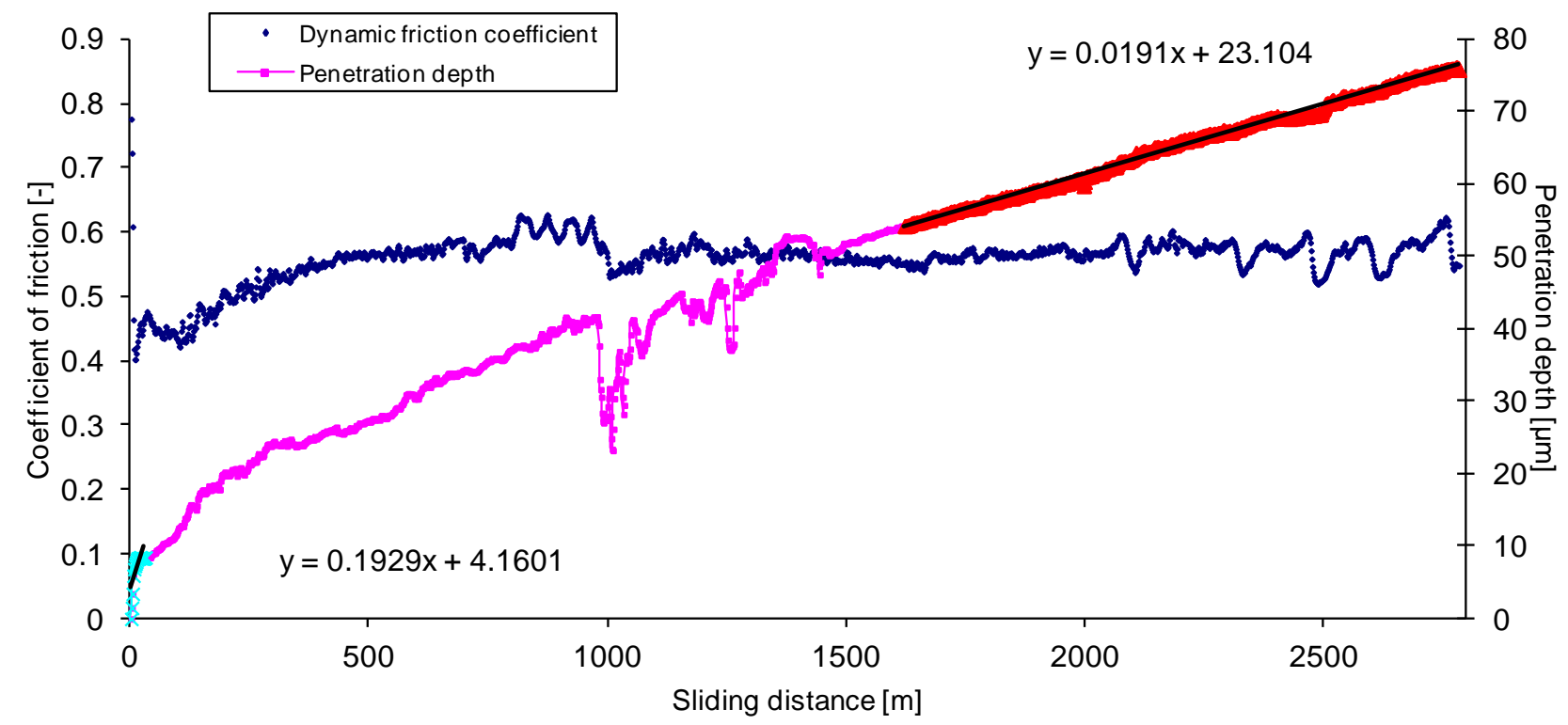

Figure 1. On-line monitoring of friction coefficient and penetration depth for $\mathrm{SiC}$ balls sliding against binderless WC flats with a contact pressure of $1.9 \mathrm{GPa}$ and a speed of $0.3 \mathrm{~m} / \mathrm{s}$

The surface profile of the SiC ball after wear testing was measured by means of surface profilometry Somicronic $\circledast$ EMS Surfascan 3D, see Figure 2. The needle was slid in the curvature of the ball and was able to measure the flattened part of the ball. The length of the flattened area was determined to be 1250 $\mu \mathrm{m}$.

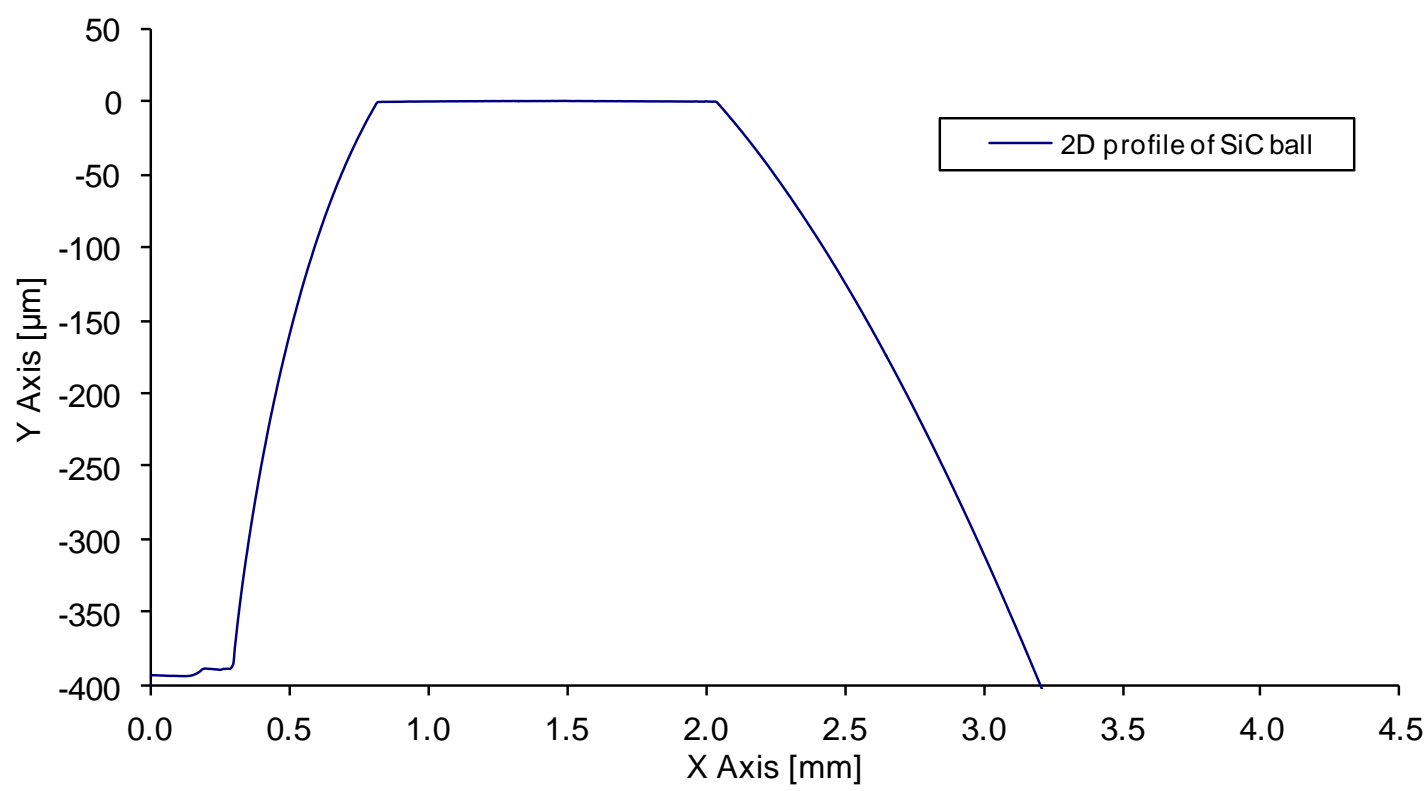

Figure 2. Post-mortem measurement of the flatness of the ball using surface profilometry Somicronic $\AA^{\mathrm{E}} \mathrm{EMS}$ Surfascan 3D.

An second post-mortem technique, optical microscopy, was used in order to validate the accuracy of the previous measurements. A micrography was captured and by means of an image analyzer it was possible 
to measure the diameter of the flattened area to be $1289 \mu \mathrm{m}$, see Figure 3 . The standard deviation between the flatness values obtained in the surface profilometry and the optical microscopy is less than $3 \%$.

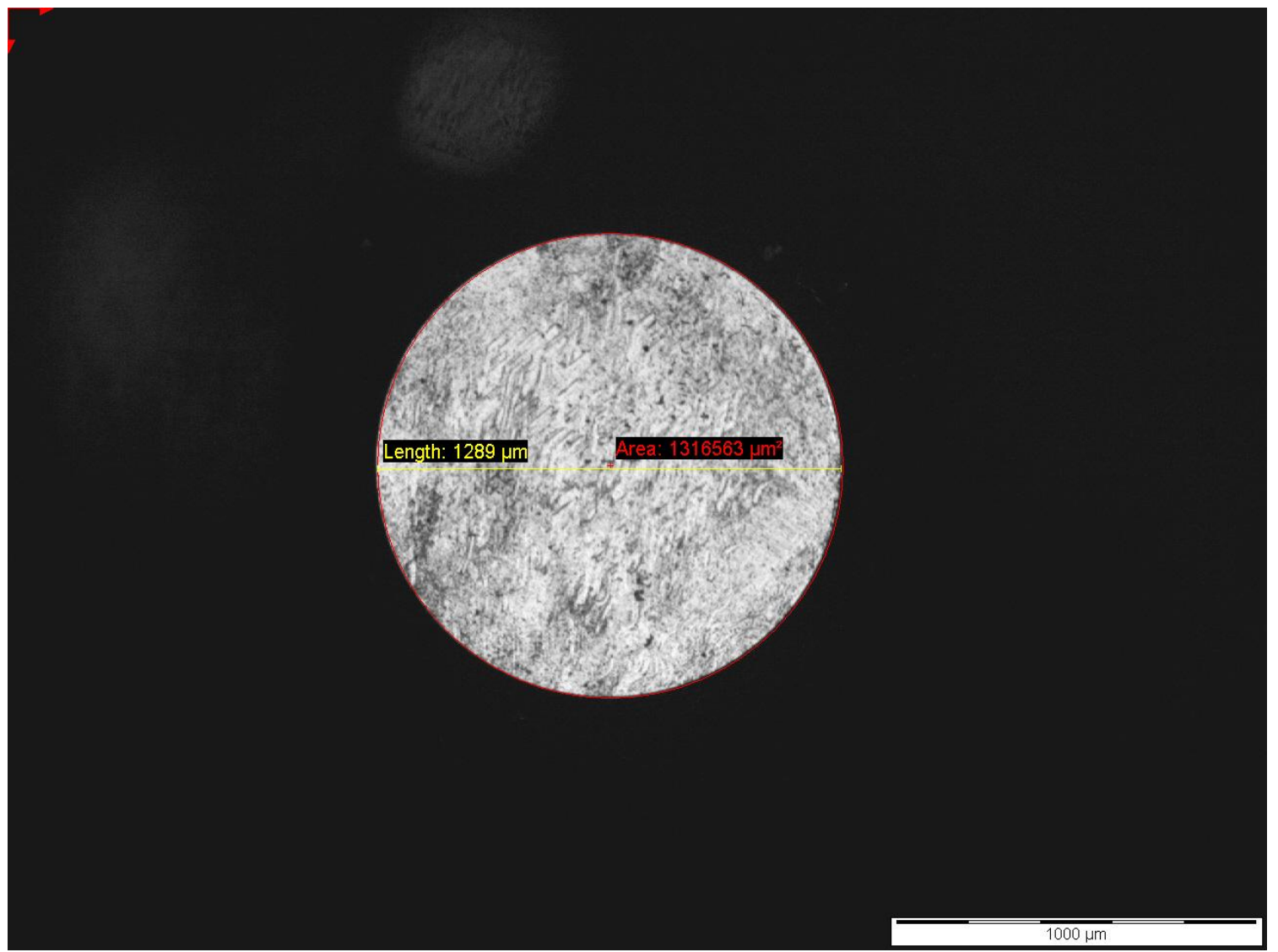

Figure 3. Optical micrography of the flatness in the SiC ball.

A geometrical analysis of the ball with the worn part was carried out. The cross section of the ball has been taken into account for a better understanding, see Figure 4 . The value ' $w$ ' represents the width of the flattened area. This value corresponds to the 'length' or 'diameter' of the flattened area as measured by surface profilometry (Fig. 2) and optical microscopy (Fig. 3), respectively.

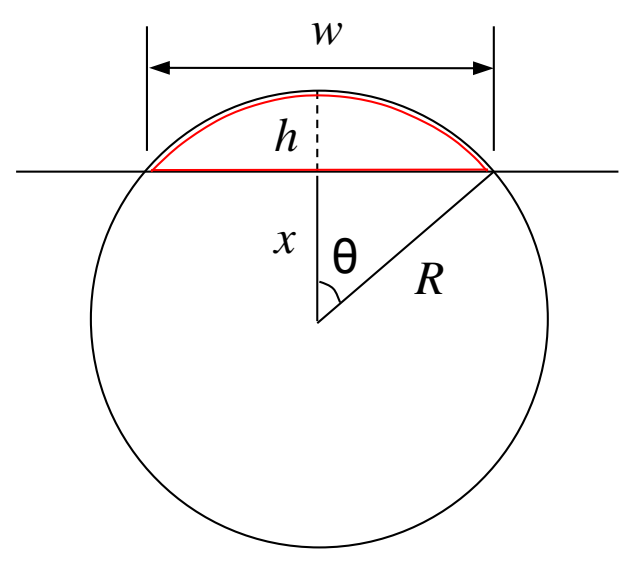

Figure 4. Geometrical analysis of the cross section of the ball, including the worn cap after the wear test.

The height of the worn cap was calculated geometrically using Eq. (1); ' w' corresponds to the measured diameter from the top view, ' $h$ ' is the height of the worn cap after sliding and ' $R$ ' represents the (initial) ball radius 


$$
h=R-x
$$

Where,

$$
\sin \theta=\frac{w / 2}{R}
$$

And,

$$
\tan \theta=\frac{w / 2}{x}
$$

Substituting ' $w$ ' in the equations (2) and (3) by the width of the flattened area of the ball measured with the surface profilometry, i.e., $1250 \mu \mathrm{m}$, yields a value of $73.68 \mu \mathrm{m}$ for the height ' $h$ ' of the worn cap of the ball. This is in good agreement with on-line penetration depth curve which reached a value of $75.81 \mu \mathrm{m}$ at the end of the sliding wear test. The penetration depth obtained in the on-line monitoring is the wear of the ball plus the wear of the disk. The wear of the disk was negligible. It was practically just a polishing in the contact surface with a depth of approximately $2 \mu \mathrm{m}$.

A linear tendency was observed in the penetration curve either in the running-in and the steady-state stage. Assuming the running-in period corresponds to the first $100 \mathrm{~m}$, which is characterized by a steep slope in the penetration depth curve and friction coefficient, see Figure 1, the penetration wear depth of the ball after that $100 \mathrm{~m}$ of sliding was calculated to be $12.48 \mu \mathrm{m}$. This observation in the running-in process shows high wear rate. Therefore, in case the SiC ball has a surface roughness of $6 \mu \mathrm{m}$, it would be completely worn off after sliding for $100 \mathrm{~m}$ against a binderless WC disk.

The linear tendency in the penetration depth curve for the steady-state stage could also be assumed for further calculations. Accordingly, the width of the flattened area of the ball for a sliding distance of $10 \mathrm{~km}$ could be predicted. Indeed, based on the geometrical wear model, the height of the worn cap of the ball at a sliding distance of $10 \mathrm{~km}$ is calculated to be $2028 \mu \mathrm{m}$. This means that a test with a sliding distance of 10 $\mathrm{km}$ under identical conditions would reduce approximately one third of the mass of the ball. However, this assumptions needs to be further investigated by means of a real wear test under the same parameters for $10 \mathrm{~km}$ and by measuring the damage in the ball using surface profilometry and optical microscopy.

\section{CONCLUSIONS}

Rotating ball-on-disk experiments on binderless WC ceramic disks surface finished by grinding and slid against $\mathrm{SiC}$ balls at room temperature revealed a typical friction and wear behaviour as a function of sliding distance. For both the friction and penetration depth curve, a running-in period was observed during the first $100 \mathrm{~m}$ of sliding. The penetration depth after running-in was found to be $12.48 \mu \mathrm{m}$. The penetration depth curve in steady-state stage could be approximated by a linear equation. Post-mortem surface topography measurement of the wear surface of the ball, together with a geometrical wear model, allowed to calculate a penetration depth which corresponded very well to the value obtained by on-line monitoring. Fluctuations in friction coefficient and penetration depth were thought to be attributed to simultaneous formation and delamination of debris layer, polishing and abrasion. The generated wear particles in the wear track will be examined more in-depth in a near future investigation. 


\section{NOMENCLATURE (OPTIONAL)}

$\begin{array}{lll}w & \text { Width of the flatness of the ball } & \mu \mathrm{m} \\ h & \text { Height lost (worn cap of the ball) } & \mu \mathrm{m} \\ R & \text { Radius of the ball } & \mu \mathrm{m} \\ x & \text { Radius reduced } & \mu \mathrm{m}\end{array}$

\section{ACKNOWLEDGEMENTS}

The authors would like to acknowledge the support of the Fund for Scientific Research Flanders (FWO, Grant No. G.0539.08) and the Flemish Institute for the promotion of Innovation by Science and Technology in industry (IWT, Grant No. GBOU-IWT-010071-SPARK).

\section{REFERENCES}

[1] M.H. Myint, J.Y.H. Fuh, Y.S. Wong, L. Lu, Z.D. Chen, C.M. Choy, Evaluation of wear mechanisms of YTZP and tungsten carbide punches, Journal of Materials Processing Technology 140 (1-3) (2003) 460 464.

[2] E. Marui, H. Endo and A. Ohira, Wear test of cemented tungsten carbide at high atmospheric temperature $\left(400^{\circ} \mathrm{C}\right)$, Tribology Letters $8(2000)$ 139-145.

[3] O. Malek, B. Lauwers, Y. Perez, P. De Baets, J. Vleugels, Processing of ultrafine ZrO2 toughened WC composites, Journal of the European Ceramic Society 29 (2009) 3371-3378.

[4] Anstis GR, Chantikul P, Lawn BR, Marshall DBA. A critical evaluation of indentation techniques for measuring fracture toughness: I, direct crack measurements. Journal of the European Ceramic Society 1981; 64 (9): 533-538.

[5] M.H. Staia, I.J. Torres, C. Castillo, T.S. Sudarshan, J. Lesage, D. Chicot, Tribological study of WC produced by plasma pressure compaction, International Journal of Refractory Metals \& Hard Materials 24 (2006) 183-188. 